\title{
EFFECTS OF SPANISH PRAGMATIC AND LEXICAL CONSTRAINTS IN THE INTERPRETATION OF L2 ENGLISH ANAPHORA ${ }^{1}$
}

\author{
Malcolm A. Finney
}

\begin{abstract}
This study examined the interpretation of English anaphora by native Spanish speakers and potential transfer of Spanish pragmatic and lexical requirements into English. It further evaluated whether appropriate contextual information might prime the preferred English interpretation of such constructions. Pragmatic and lexical rules governing co-indexation in Spanish and English anaphora constructions differ substantially and operate quite differently in the two languages. Spanish pragmatic rules require obligatory disjoint reference for subject pronominals in finite complement subjunctive clauses and pre-posed adjunct clauses. The lexical properties of verbs and anaphora in reflexive, reciprocal, and intransitive constructions in Spanish require obligatory retention of the anaphora element. English has no such pragmatic or lexical requirements. The study appraised the effects of the different pragmatic co-indexation requirements and different lexical requirements on the interpretation of English anaphora by native Spanish speakers. An act-out task, a corresponding written task, and a grammaticality judgement task in English were administered to adult native English speakers and adult native Spanish speakers categorized as intermediate and advanced learners of English. Subjects were instructed to match pronominals with appropriate referents in English subjunctives and pre-posed adjuncts. They were further required to judge the acceptability of sentences containing anaphora elements in English reflexives, reciprocals, and intransitives. Results indicated that subjects in general ignored pragmatic and lexical requirements of the first language in favour of the second language requirements governing anaphora. Less proficient subjects apparently encountered some processing difficulty when interpretation of sentences with anaphora was required within limited time constraints. The use of contextual information was also evident in the interpretation of some constructions.
\end{abstract}

Keywords: Anaphor (Anaphora), Antecedent, Binding theory (BT), Null pronominal languages, Intransitive (Decausative) constructions.

\section{Introduction}

The term 'anaphora' is generally used to refer to a form whose interpretation is dependent on a referent that is present in the same sentence or is mentioned in a preceding discourse. For an accurate interpretation of anaphora, language users may have to tap into a linguistic system of interactive components. The choice of antecedent is dependent on syntactic, lexical, pragmatic, and discourse knowledge of how these constructions work in different

\footnotetext{
${ }^{1}$ I wish to acknowledge the invaluable help of my research assistant, Hiromi Pat Noda, in running the experiments and statistically analyzing the data.
} 
languages. This study examined the interpretation of English anaphora by Spanish speakers, to determine whether adult native Spanish speakers would inappropriately transfer the pragmatic and lexical requirements governing Spanish anaphora into English. The study focused on two specific issues. It explored the possibility of adults transferring the pragmatic requirements governing co-indexation of pronominals in subjunctives and preposed adjuncts in their L1 (Spanish) - a 'pragmatic' language - in the interpretation of similar constructions in L2 (English) - a 'syntactic' language. These issues were addressed in an act-out task and a corresponding written task. The possible use of contextual information in priming the preferred English interpretation of pronominals was also explored in these tasks. The study in addition examined the significantly different lexical requirements for verbs and anaphora elements in reflexives, reciprocals, and intransitives in L1 (Spanish) and L2 (English) and the possible transfer of L1 lexical requirements in the interpretation of these constructions in L2. These issues were addressed in a grammaticality judgement task.

The interpretation of anaphora is dependent on the knowledge of the different processing components including syntactic, lexical, pragmatic, and discourse elements. This study attempts to account for anaphoric relationships both within and beyond the sentential level; results may therefore have important implications not only for researchers working on language acquisition but also for those working within semantic/pragmatic, lexical, and discourse frameworks.

The paper first presents the structural requirements of the binding theory (section 2) followed by a discussion of general pragmatic constraints that further restrict the coindexation requirements of anaphora in 'pragmatic' languages including Spanish but not in 'syntactic' languages like English (section 3). Next the paper discusses lexical requirements in the interpretation of anaphora, including the lexical differences in the properties of verbs and anaphora elements used in reflexives, reciprocals, and intransitives in Spanish and English (section 4). A description of the study (including the experiments) follows in section 5 . In this section, the paper argues for the establishment of pragmatic and lexical requirements in L1 (Spanish) and the possibility of transfer of such requirements in L2 (English). Possible use of contextual information by L2 learners is partly evaluated as well. Section 6 provides information on the subjects used in the study, followed by a presentation and discussion of results of the study in section 7. Conclusion remarks, presented in section 8 , include a summary and limitations of the study, as well as suggestions for future research.

\section{The binding theory and the interpretation of pronominals}

Principles of the Binding Theory (BT), according to the standard Government and Binding approach, outline syntactic (structural) requirements constraining the choice of referents for anaphora. A pronominal is required to be free within its local domain - the minimal clause containing the pronominal. Further, the referent, selected from outside this domain, should not be preceded and c-commanded by the pronominal. This condition generally holds in English:

1) he * $_{*_{i} / * j / k}$ said that John telephoned his friend $_{j}$. 
2) Before he ${ }_{i / j / \mathrm{k}}$ left, $\mathrm{John}_{\mathrm{i}}$ telephoned his friend $\mathrm{j}_{\mathrm{j}}$

In (1), the pronominal both precedes and c-commands the matrix NPs John and his friend. The BT rules out co-indexation with either of these NPs. The antecedent has to be an external referent. In (2), the pronominal in the pre-posed adverbial (adjunct) clause precedes but does not c-command the lexical NPs John and his friend. The BT does not rule out co-indexation with either of these NPs or with an external NP.

Constraints on binding in English, to a large extent, are structural. In Spanish subjunctive and pre-posed adjunct constructions, however, pragmatic constraints may further restrict the application of the BT on pronominals. Thus Spanish speakers may transfer such constraints in the interpretation of similar constructions in English, a language with few, if any, pragmatic requirements in anaphoric relationships.

\section{Pragmatic constraints and the interpretation of anaphora}

\section{1. 'Pragmatic' vs. 'syntactic' languages in the interpretation of anaphora}

A number of researchers (Dalrymple 1993; Huang 2000; Lujan 1985, 1986; Padilla 1990; Wexler \& Manzini 1987) have proposed that determining the referent(s) of anaphora in Spanish as well as in a number of languages is dependent not only on syntactic constraints but also on pragmatically specified restrictions governing co-indexing. What constitutes a local domain may be determined by pragmatic properties, which differ from language to language, and from one construction to another. Huang (2000) argues for a Neo-Gricean pragmatic theory of anaphora in which constraints on co-indexation are pragmatically motivated. Languages do vary however in the extent to which pragmatics plays a role in sentence interpretation. Huang classifies some languages as 'pragmatic' languages (e.g. Chinese, Japanese, Korean) since constraints on anaphora are to a large extent determined not only by pre-determined structural constraints but also by language use. Characteristics of prototypical pragmatic languages include (Huang 2000: 262) "massive occurrence of zero anaphors, existence of pragmatic zero anaphors or empty pragmatic categories, [and] pragmatic obligatory control ...". Languages like English, French, and German, which lack these properties, are considered prototypical syntactic languages. A number of studies have thus contended that obligatorily bound or disjoint interpretation of anaphora in a number of languages may be associated not only with syntactic (structural) requirements but also with specific pragmatic properties of the anaphoric elements or the structures in which they occur.

\subsection{Pragmatic constraints in the interpretation of pronominals in subjunctive constructions}

One such 'pragmatic' language is proposed to be Icelandic. Wexler \& Manzini (1987) and Huang (2000) propose that binding constraints for reflexives in Icelandic are pragmatically determined - by the mood of the sentence: Indicative or Subjunctive. Huang argues that the speaker's attitude towards the truth condition of the sentence determines the choice of 
anaphora and constraints on the binding domain: Whether the speaker asserts that the statement is true (indicative) or does not take responsibility for the truth condition of the sentence (subjunctive). The binding domain for the reflexive sig is the minimal finite indicative clause. For example (Wexler \& Manzini 1987):

3) a. $\quad{ }^{*} \mathrm{Jon}_{\mathrm{i}}$ segir ad [Maria elskar sig s $_{\mathrm{i}}$ Jon $_{i}$ says that Maria loves REFL $_{i}$

b. $\quad$ Jon $_{\mathrm{i}}$ segir ad [Maria elski sig $\left._{\mathrm{i}}\right]$ Jon $_{i}$ says that Maria loves (subjunctive) REFL $_{i}$

Example (3a) is ungrammatical because the antecedent is external to the embedded clause, which is the binding domain. The matrix clause is the binding domain in (3b) since the mood is subjunctive. The indicative/subjunctive asymmetry however does not apply to the pronominal hann:

4) a. Jon $n_{i}$ segir ad [Maria elskar hann $\left.{ }_{i}\right]$

Jon $_{i}$ says that Maria loves him $_{i}$

b. $\quad$ Jon $_{\mathrm{i}}$ segir ad [Maria elski hann ${ }_{\mathrm{i}}$ ]

$\mathrm{Jon}_{\mathrm{i}}$ says that Maria loves (subjunctive) him $_{\mathrm{i}}$

In line with proposals by Wexler \& Manzini (1987) and Huang (2000), binding domains for indicative and subjunctive constructions in Spanish are arguably restricted by pragmatic constraints as well. These constraints however do not apply in a 'syntactic' language like English. In the following English sentence:

5) John demands that he visit the museum

the pronominal he could refer to John or to any other male though John would likely be the preferred referent in English. In the following Spanish examples, the null pronominal (pro) in (6) has free co-reference. It could select a referent from the sentence, such as Juan, or from a preceding discourse. In (7), the null pronominal is prohibited from being co-referent with the matrix subject Juan. In (7a), Juan wants someone other than himself to keep the secret, and in (7b) Juan wants someone other than himself to accept the task (Padilla 1990):

6)

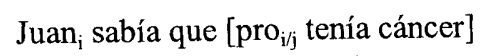

Juan knows that 3 rdS has cancer

7) a. Juan ${ }_{i}$ quería que [pro $*_{i j j}$ guardara el secreto]

Juan wanted that [3rdS keep the secret]

b. Juan $n_{\mathrm{i}}$ obligó a Lola $\mathrm{j}_{\mathrm{j}}$ a que [pro * $/ \mathrm{j}$ j $_{\text {aceptara el encargo] }}$

Juan forced Lola that [3rdS accept the task]

Subjunctive constructions, on the other hand, are sometimes used to express speech acts 
such as desires, requests, commands, and prohibition, as in (7). A pronominal in such constructions could have a matrix subject as co-referent in a non-null pronominal language like English, and stress may be used to signal a disjoint interpretation of the pronominal. That is, stress could be used to resolve a potential ambiguity. For languages in which a null pronominal is used in such constructions, potential ambiguity could be reduced or eliminated by imposing disjoint interpretation of the null pronominal. That is, the interpretation of pronominals in some Spanish subjunctive constructions may be constrained by a pragmatic requirement that a null pronominal subject in an embedded clause be obligatorily disjoint from the subject of the matrix clause. ${ }^{2}$

Pragmatic constraints thus play a more prominent role in languages with an abundance of zero anaphors, including Spanish, possibly to resolve ambiguities associated with zero anaphors. In languages like English, which utilize a lot more overt anaphors, co-indexation of anaphora tends to be more structure dependent.

\subsection{Pragmatic constraints in the interpretation of pronominals in pre-posed adjunct clauses}

In Spanish, a pronominal (overt or null) in a finite post-posed adjunct clause could be coindexed with a matrix subject or object, or an external referent in accordance with the BT though a disjoint interpretation is preferred for a null pronominal. A pragmatic constraint however restricts co-indexation requirements for a pre-posed lexical subject pronominal: It has to be obligatorily disjoint from the subject NP in the following matrix clause, as is the case in (10):

8) Juan ${ }_{\mathrm{i}}$ no bebe cuando él $\mathrm{i}_{\mathrm{i} j}$ trabaja

"Juan doesn't drink when he works"

9) a. Cuando pro $_{i / j}$ trabaja, Juan $_{i}$ no bebe

"When he works Juan doesn't drink"

b. Si pro ${ }_{i / j}$ no duerme, Ana $_{i}$ se irrita

"If she doesn't sleep Ana gets irritated"

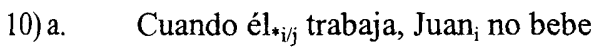

"When he works, uan doesn't drink"

b. Si ella $*_{*_{j} / j}$ no duerme, Ana se irrita

If she doesn't sleep Ana gets irritated

In (10a), the pronominal he could refer to Juan or any other male though Juan is the preferred choice in English. In Spanish, it has to refer to any male except Juan. In (10b), the

\footnotetext{
${ }^{2}$ This requirement may not be applicable to all Spanish subjunctive constructions. The following are provided as counterexamples in Spanish to the proposed subjunctive requirement: 1) El niño quiere que sea reconocido como tál; 2) Espero que pueda estudiar para que pueda tener un buen trabajo.
} 
pronominal she could refer to Ana or any other female though Ana is the preferred choice in English. In Spanish, it has to refer to any female except Ana. A major difference however between English and Spanish is that the pronominal is always explicitly required in English but may be implied (i.e. null) in Spanish. When the pronominal is null in Spanish, the restriction does not apply. For example:

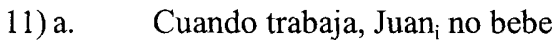

"When (he) works Juan doesn't drink"

b. Si no duerme, Ana se irrita

"If (she) doesn't sleep Ana gets irritated"

The explicit use of the pronominal in a pre-posed adjunct clause, compared to when the pronominal is implied, is a pragmatic indication that emphasis or contrast is desired. Huang (2000) proposes that the principles of emphaticness or contrastiveness could influence the interpretation of anaphora. He identifies two categories of languages: Those that do not distinguish between emphatics and anaphora - Finno-Ugric, Semitic, and Turkic languages - and those that do - Germanic (excluding English), Romance, and Slavic languages. In the latter, he asserts that emphaticness or contrastiveness could trigger some semanticopragmatic conditions that emphasis or contrast is desired. He argues that the use of overt or null pronominals is related to these principles. The use of an overt pronoun is an indication of emphaticness or contrastiveness and that this is prevalent in a number of Null Pronominal Languages (NPL). In such languages, a pronominal is generally null but is used overtly to signal emphasis or contrastiveness. This is applied in a number of languages including Arabic, Bengali, Catalan, Chinese, Italian, Korean, Polish, Spanish, Swahili, and Turkish (Huang 2000: 232).

The principles of Emphaticness and Contrastiveness, according to Huang, stem from the more general principles of Overt Pronoun Constraint (Montalbetti 1984) and the Condition on Arbitrary Pronominals (Jaeggli 1986). The Overt Pronoun Constraint prohibits an overt pronominal from being linked to an antecedent if it occurs in a position where it could alternate with a null pronominal. The Condition of Arbitrary Pronominals prohibits a pronominal from being arbitrary in reference if it occurs in a position where it could alternate with a null pronominal.

Thus, the use of an overt pronominal in Spanish as in (10) is a signal that a disjoint interpretation is intended. This is triggered by a pragmatic constraint that when a pronominal is used explicitly in a pre-posed adjunct clause, the desired interpretation is different from the interpretation when the pronominal is implied.

A similar view is expressed by Lujan $(1985,1986)$ who proposes that Null Pronominal Languages (NPLs) (including Spanish, Italian, Portuguese, Malayalam, Chinese, and Japanese) invoke a condition that blocks co-indexation between a pre-posed lexical pronominal and a following lexical NP subject. Selection of a matrix object antecedent in the same structure, though questionable, is not ungrammatical:

12) ?Cuando no lo invitan a él ${ }_{i}, J_{u a n}$ se ofende When they don't invite him $_{\mathrm{i}}$, Juan $_{\mathrm{i}}$ takes offense 
According to Lujan (1985, 1986), lexical pronominals in NPLs are contrastive and are always stressed in positions where they may alternate with null pronominals. This is similar to contrastive stress in non-NPLs with an unstressed pronoun corresponding to a null pronoun in NPLs. Lujan proposes a Universal Precedence Constraint that stressed pronouns cannot precede their antecedents where they may alternate with null or unstressed pronouns. A subject pronominal in NPLs is generally omitted unless it has the same functions as a stressed pronominal in non-NPLs where contrastive stress would result in a preferred disjoint reference from the matrix subject NP. When a lexical pronominal occurs in positions where no alternation is allowed with a null pronominal (e.g. conjoined NPs, object of prepositions, etc.), obligatory disjoint interpretation with the subject is not required even if the pronominal precedes the antecedent:

\section{3) Cuando él $\mathrm{l}_{\mathrm{i} j}$ y su mujer trabajan, Juan ${ }_{\mathrm{i}}$ no bebe \\ "Cuando pro y su mujer trabajan, Juan no bebe \\ When he and his wife work, Juan doesn't drink}

The choice of antecedent in anaphora constructions in a number of languages is thus determined, to some extent, by pragmatic properties associated with the anaphora construction. In English, for example, pronominals are always overt with only one lexical form associated with each gender. Interpretation of the pronominal, when unstressed, is free though the matrix subject is generally the preferred antecedent. Stress is sometimes assigned on the pronominal as an indication that an unlikely antecedent - a non-subject or one mentioned in preceding discourse - is intended. Other languages (including Spanish) have different representations of anaphora elements or specific anaphora constructions associated with different pragmatic properties. The factors that induce obligatory disjoint interpretation are pragmatic constraints, which, as Lujan points out, operate at the discourse level.

\section{Lexical requirements in the interpretation of anaphora}

\subsection{Lexical properties of anaphoric elements and constraints on co-indexation}

In addition to structural and pragmatic differences in the interpretation of anaphora, languages may further differ in the lexical properties associated with the anaphora element or with the verbs used in the construction. This has prompted some researchers (Borer 1984; Wexler \& Manzini 1987) to conclude that parametric variation across languages may be associated not with particular structures across languages but with particular lexical items within languages.

The Norwegian reflexive has two lexical representations: ham selv, which must be bound to a non-subject, and seg selv, which, in contrast, must be bound to the surface subject (Dalrymple 1993):

14) a. Vi fortalte $\mathrm{Jon}_{\mathrm{i}}$ om ham selv We told Jon $_{i}$ about selfi 
b. $\quad{ }^{*} J n_{i}$ snakker om ham selv $_{i}$ Jon $_{i}$ talks about self $i$

c. jeg ga Jon $_{\mathrm{j}}$ en bok om ham selv ${ }_{*_{\mathrm{i}} / \mathrm{j}}$

$\mathrm{I}_{\mathrm{i}}$ gave Jon $_{\mathrm{j}}$ a book about self $\mathrm{*}_{\mathrm{i} / \mathrm{j}}$

15) a. Jon fortalte meg om seg selv Jon $_{\mathrm{i}}$ told me about self

b. $\quad{ }^{*}$ Vi fortalte $\mathrm{Jon}_{\mathrm{i}}$ om seg selv $\mathrm{i}_{\mathrm{i}}$

We told Jon about self $_{\mathrm{i}}$

A similar alternation is proposed by Pulleyblank (1986) to occur between the weak pronoun $o$ and the strong pronoun oun in Yoruba. The weak but not the strong pronoun must be disjoint from subjects in finite and non-finite clauses Replacing the weak pronoun with the strong one in Yoruba would induce the choice of the subordinate subject as antecedent:

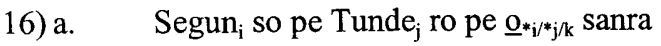

Segun $_{\mathrm{i}}$ said that Tunde $\mathrm{j}_{\mathrm{j}}$ thought that he $\boldsymbol{*}_{\mathrm{i}_{\mathrm{i} / \mathrm{j} / \mathrm{k}}}$ was fat

b. $\quad \operatorname{Tolu}_{\mathrm{i}}$ so fun $\operatorname{Segun}_{\mathrm{j}}$ pe Dupe $\mathrm{k}_{\mathrm{k}}$ ro pe $\underline{\mathrm{o}}_{* i j / *_{\mathrm{k}}}$ sanra

Tolu $_{\mathrm{i}}$ told Segun $\mathrm{j}_{\mathrm{j}}$ that Dupe $\mathrm{k}_{\mathrm{k}}$ thought that he ${ }_{*_{\mathrm{i} j} / *^{*} \mathrm{k}}$ was fat

As the above examples illustrate, languages do have different properties or requirements associated with lexical items in anaphoric constructions.

\subsection{Lexical requirements in the interpretation of anaphora reflexives, reciprocals and intransitive (decausative) constructions in Spanish and English}

Reflexives are generally obligatorily overt in English and Spanish. In English, however, the lexical properties of some verbs allow optional deletion or omission of the reflexive pronoun, if implied, while the equivalents of such verbs in Spanish do not (Whitley 1986: 176):

$\begin{array}{ll}\text { Pedro } & \text { SPANISH } \\ \text { se lavó } \\ \text { se vistió } \\ \text { se afeitó } \\ \text { se bañó }\end{array}$

Peter $\begin{aligned} & \text { ENGLISH } \\ & \text { washed (himself), washed up } \\ & \text { dressed (himself), got dressed } \\ & \text { shaved (himself) } \\ & \text { bathed (himself), took a bath }\end{aligned}$

A similar phenomenon occurs with reciprocals as well. The reciprocal and reflexive markers are homophonous in Spanish - /se/ and a plural reflexive may be ambiguous if emphasizers are not used. In any case such a marker has to be used explicitly (Whitley 1986: 177): 
Todos se miraron

Everyone looked at himself/herself/each other

Use of the English reciprocal marker is optional. It could be overt or implied:

$$
\begin{aligned}
& \text { They agreed (with each other) } \\
& \text { We argued (with each other) } \\
& \text { You got married (to each other) } \\
& \text { They fought (one another) }
\end{aligned}
$$

Whitley (1986: 179) further draws attention to the obligatory retention of/se/ by verbs in Spanish Intransitive or Decausative constructions. In English, however, the anaphora element is implied but obligatorily omitted for similar verbs in such constructions:

\section{SPANISH}

20)

Ella se detuvo en el andén
El aluminio se ha fundido
Los vasos se rompen
El barco se hundirá

\section{ENGLISH}

She stopped (*herself) on the platform

The aluminum has melted $(*$ itself)

Glasses break (*themselves)

The boat will sink (*itself)

NOTE: The asterisks indicate that the bracketed forms are not allowed.

Differences in the obligatory/optional use or omission of reflexive, reciprocal, and intransitive constructions are thus triggered by the lexical properties of the anaphora elements and the verbs that they occur with. These requirements differ from language to language and are possible candidates for transfer in the use of anaphora in a second language.

\section{The study}

\subsection{Hypotheses}

One of the prevalent views in the 1960's was that the acquisition of a second language was greatly influenced by the linguistic properties of the learner's native language, with the implication then that errors in $\mathrm{L} 2$ would be predictable by a contrastive analysis of $\mathrm{L} 1$ and L2. This argument was based mainly on the strong version of the Contrastive Analysis Hypothesis (CAH), which claimed that all L2 errors could be predicted by a systematic comparison between the native language and the target language. The CAH has since come under severe criticism primarily because of its lack of predictive powers. Not all differences between $\mathrm{L} 1$ and $\mathrm{L} 2$ result in errors, and the CAH could not predict the areas of differences between $\mathrm{L} 1$ and $\mathrm{L} 2$ that are likely to result in errors. In addition, some errors are evident only during the early stages of $\mathrm{L} 2$ acquisition while others persist in spite of increasing competence in L2. The CAH could not predict which errors are likely to be temporary and which errors are likely to persist in spite of increasing competence in L2.

The primary goal of this study was to test whether the pragmatic and lexical rules of $\mathrm{L} 1$ would be transferred into $\mathrm{L} 2$. The saliency of pragmatic constraints governing pronominal 
co-indexation in subjunctive and pre-posed adjunct constructions in Spanish (a pragmatic language) could result in inappropriate transfer of such constraints in the interpretation of similar constructions in English (a syntactic language) by native Spanish speakers. Similarly, the striking differences between lexical requirements of anaphora elements and verbs in reflexive, reciprocal, and intransitive constructions in Spanish and English could trigger a transfer of such requirements in the grammaticality judgement of similar constructions in English by native Spanish speakers.

Two hypotheses were therefore evaluated by the study:

\section{Pragmatic Hypothesis}

Spanish speakers would transfer Spanish pragmatic constraints governing pronominal coindexation in their interpretation of subjunctive and pre-posed adjunct constructions in English.

\section{Lexical Hypothesis}

Spanish speakers would transfer Spanish lexical requirements of anaphoric elements and verbs in their judgment of reflexive, reciprocal, and intransitive constructions in English.

In the event of evidence of transfer, the study additionally set out to determine if transfer of pragmatic and lexical properties of Spanish would be evident only in learners with lower English competence or in learners at different levels of competence in English.

\subsection{Use of contextual information in adult sentence interpretation}

Research on adult sentence processing indicates that adults do make use of contextual information, when available, in attempting to resolve ambiguities in sentences in L1 (Altmann 1988; Taraban \& McClelland 1988). Altmann (1988) and Taraban \& McClelland (1988) conducted studies involving the interpretation of potentially ambiguous sentences in English by native English speakers and concluded that subjects resolved potential ambiguities by utilizing semantic and contextual information provided. Adults thus do utilize contextual information in sentence interpretation in their L1, and this study was designed to determine whether contextual information provided would prime the preferred interpretation of anaphora in L2 English. That is, the study additionally evaluates the use of contextual information in L2.

\subsection{Experimental tasks}

Three experiments - an act-out task, a corresponding written task, and a grammaticality judgement task - were administered. The first two tasks evaluated the possible transfer of Spanish pragmatic constraints in the interpretation of subjunctives and pre-posed adjuncts in L2 English. The third task - grammaticality judgement task - evaluated the possible transfer of Spanish lexical rules governing reflexive, reciprocal, and intransitive constructions in L2 English. 


\subsubsection{Act-out task}

In the act-out task, subjects were instructed to act out English sentences, including subjunctive and pre-posed adjunct constructions, heard on audiotape using a doll family provided. There was a ten-second interval between sentences used in this task and subjects were required to act the sentence out during this ten-second interval. This made it possible to test not only subjects' knowledge of the conventions governing co-indexation of pronominals but also their ability to process and interpret the test sentences within the time limit imposed. This presented the opportunity to evaluate whether transfer pragmatic constraints of L1 into L2 could have been triggered by subjects' inability to process the test sentences within the relatively short time provided without help from their L1. The first section of this task contained sentences designated as control sentences. These were anaphoric constructions for which interpretation of pronominals was the same in English and Spanish. For example:

\section{Post-posed Adjunct Clause with Pronominal Subject}

21) Sue sings to Kate after she plays with the dog

\section{Pre-posed Adjunct Clause with Subject Anaphor}

22) Before reading, Sue kisses dad

The expectation was that with similar constraints in English and Spanish, choice of antecedent should not be influenced by linguistic background or by proficiency level.

The second section contained sentences classified as experimental sentences. These were anaphoric constructions in English with different co-indexation requirements for similar sentence types in Spanish. These were constructions containing a pronominal in subjunctive complement clauses and pre-posed adjunct clauses. Each experimental sentence was preceded by a lead sentence that contained the same verb as that in the experimental sentence thus promoting a link between the two sentences. However, half of the lead sentences contained contextual cues leading to an interpretation that promotes coindexation of the pronominal with the matrix subject in the experimental sentence. The verb in such lead sentences was used intransitively or with a direct or prepositional object argument corresponding to the argument structure of the verb in the following subjunctive or pre-posed adjunct clause. In addition, the subject NP in the lead sentence was the same as the matrix subject NP in the following experimental sentence to promote assignment of the subject in the lead sentence as subject of the one that followed. The other half of the lead sentences was designed to be neutral. The subject of the lead sentence and that of the following subjunctive or pre-posed adjunct construction were different. Without this lead, the antecedent of the pronominal could be either the matrix subject or object NP, or any external referent that agreed in gender with the pronominal. For this study, verbs used in the subjunctive constructions were restricted to those whose Spanish counterparts also triggered the subjunctive mood. For example:

\section{Subjunctive Construction with Discourse Favouring Matrix Subject as Antecedent} 23) Mom likes kissing the family 
Mom proposes that she kiss Tom

Subjunctive Construction with Neutral Discourse

24) The family likes reading books and magazines

Dad demands that he read the book

Pre-posed Adjunct Construction with Discourse Favouring Matrix Subject as Antecedent

25) Sue likes going for a walk

After she goes for a walk, Sue reads to Kate

Pre-posed Adjunct Clause with Neutral Discourse

26) The family loves eating fruits

After he eats an orange, Tom lifts Jack

\subsubsection{Written task}

In the corresponding written task, subjects were presented with English sentences similar to those used in the act-out task. Like the act-out task, constructions used were classified as control or experimental sentences. Each sentence in this task was followed by a multiplechoice question requesting them to identify the antecedent for the pronominal. The choices included both a subject and non-subject antecedents. For example (examples (27) and (28) are samples of control sentences and examples (29) to (32) are samples of experimental sentences):

Post-posed Adjunct Clause with Pronominal Subject

27) After having a bath, dad reads to mom

Q: Who was having a bath?
a) dad
b) mom
c) Tom

\section{Pre-posed Adjunct Clause with Subject Anaphor}

28) Jack tickles Tom after he eats a banana

$\mathrm{Q}$ : Who was eating a banana?
a) Tom
b) Jack
c) dad

Subjunctive Construction with Discourse Favouring Matrix Subject as Antecedent

29) Jack loves working in the garden

Jack requests that he work in the garden

Q: Who is likely to work in the garden?
a) Tom
b) dad
c) Jack

\section{Subjunctive Construction with Neutral Discourse}

30) The family likes exercising in the gym

Dad proposes that he exercise in the gym

$\mathrm{Q}$ : Who is likely to exercise in the gym?
a) dad
b) Jack
c) Tom

Pre-posed Adjunct Construction with Discourse Favouring Matrix Subject as Antecedent 
31) Tom likes listening to music

After he listens to music, Tom dances with dad

$\mathrm{Q}$ : Who was listening to music?

a) dad

b) Tom

c) Jack

\section{Pre-posed Adjunct Clause with Neutral Discourse}

32) The family likes running around the house

After she runs around the house, Sue dances with Kate

Q: Who was running around the house? a) Kate

b) Sue

c) mom

A major difference between this task and the act-out task was that no time constraint was imposed for subjects to respond to the sentences. The primary reason for this was to see if there was a significant difference in the occurrence of transfer between the oral and written tasks. A significantly higher incidence of transfer in the oral task compared to the written could be attributed to the inability to block out the influence of L1 pragmatics when time constraints were imposed. As such, the transfer of L1 pragmatic constraints could have been triggered by processing difficulty created by the time constraints rather than by lack of knowledge of $\mathrm{L} 2$ conventions.

\subsubsection{Grammaticality judgement task}

In the grammaticality judgement task, subjects were presented with a number of grammatical and ungrammatical sentences in English and were asked to judge whether each sentence was grammatical or not. Sentences used included overt and implied reflexives, reciprocals, and intransitives, similar to the constructions discussed in section 7. Each sentence was to be ranked according to the scale:
4) Grammatical
3) Somewhat Grammatical
2) Somewhat Ungrammatical 1) Ungrammatical

For those ranked less than (4), subjects were expected to provide a grammatical equivalent or preferred alternative on the line below each sentence. For example:

\section{Overt Reflexive}

33) Susan dressed herself before attending the dinner

\begin{tabular}{|l|l|l|l|}
\hline 4 & 3 & 2 & 1 \\
\hline
\end{tabular}

\section{Implied Reflexive}

34) Peter washed after working on his car

\begin{tabular}{|l|l|l|l|}
\hline 4 & 3 & 2 & 1 \\
\hline
\end{tabular}

\section{Overt Reciprocal}

35) The couple that lived next door got divorced from each other last month 


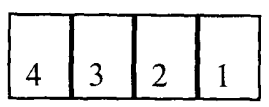

\section{Implied Reciprocal}

36) The boys fought over an apple

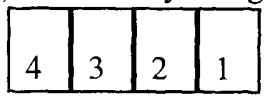

\section{Overt Intransitive}

37) The glasses in the cabinet broke themselves during the earthquake

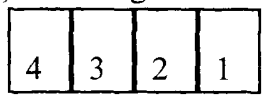

\section{Implied Intransitive}

38) The wine spilled on the floor

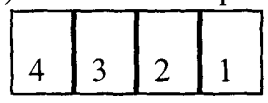

\section{Ungrammatical Filler Sentence}

39) The waiter the tray dropped while it carrying to the table

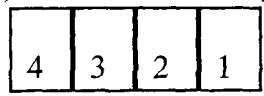

\section{Selection of subjects}

A control group of 20 adult native English speakers and an experimental group of 33 adult native Spanish speakers, most of them students at California State University Long Beach, participated in the study. The minimum age requirement to participate in this research was 18 years. 15 of the Spanish subjects grew up in Hispanic communities in the Western United States; 7 grew up in Mexico; the rest grew up in a variety of Spanish speaking countries in Central and South America including Argentina, Chile, Columbia, Cuba, Costa Rica, and Venezuela. Levels of proficiency for the Spanish subjects were determined by a cloze test that was administered to all subjects (including the native English speakers) prior to the start of the experiments. Spanish speakers of two proficiency levels were used in order to evaluate the extent to which competence level in L2 played a role in interpreting anaphora in L2. There were no beginners used in this study because of the potential difficulty in understanding the English vocabulary and complexity of some of the constructions used in the experiments. 


\section{Results and discussion}

Pragmatic and lexical rules play a prominent role in anaphoric relationships in Spanish. The establishment of these rules in L1 could lead native Spanish-speaking adults to assume that these rules are in operation in L2 English and hence transferred in their interpretation and use of anaphora in English.

\subsection{Act-out and written tasks: Control sentences}

Control sentences were sentences for which co-indexation requirements were the same in English and in Spanish. They were used in the first section of the experimental tasks and included pre-posed adjunct clauses containing a null subject pronominal and post-posed adjunct clauses containing a lexical pronominal (See examples (21), (22), (27), and (28)). A pre-posed adjunct clause with a null subject obligatorily requires a subject antecedent in both English and Spanish. In a post-posed adjunct clause in both English and Spanish, a subject antecedent is the preferred, not obligatory, choice. Results are presented in tables 1 and 2 . The percentage scores are followed by the total number of responses by the subjects combined for each sentence type, in parentheses, for each construction type:

\section{Table 1: Percentages of Subject Choice in Control Sentences (Act-out Task)}

\begin{tabular}{lll}
\hline Subjects & Pre-posed Adjuncts with Null Subjects & Post-posed Adjuncts \\
\hline English & $100 \%(60 / 60)$ & $91.7 \%(55 / 60)$ \\
\hline Advanced & $100 \%(54 / 54)$ & $88.9 \%(48 / 54)$ \\
\hline Intermediate & $91.1 \%(41 / 45)$ & $95.6 \%(43 / 45)$ \\
\hline
\end{tabular}

Table 2: Percentages Subject Choice in Control Sentences (Written Task)

\begin{tabular}{lll}
\hline Subjects & Pre-posed Adjuncts & Post-posed Adjuncts \\
\hline English & $100 \%(60 / 60)$ & $68.3 \%(41 / 60)$ \\
\hline Advanced & $96.1 \%(49 / 51)$ & $79.6 \%(43 / 54)$ \\
\hline Intermediate & $95.6 \%(43 / 45)$ & $75.6 \%(34 / 45)$
\end{tabular}

A subject antecedent was the unanimous choice for pre-posed adjuncts for the English as well as the advanced Spanish subjects in the act-out task. A one-way ANOVA test was used to assess the performance of the three groups of subjects (English, native Spanish speakers 
with advanced competence in English, and native Spanish speakers with intermediate competence in English) on the choice of a subject antecedent in the control sentences of both the act-out and written experiments. The three groups did differ significantly on the choice of subjects: $\underline{\mathrm{F}}(2,50)=6.52, \underline{\mathrm{p}}<.01$. An independent $\mathrm{t}$-test used to assess the significance of the one-way ANOVA revealed that there was a significant comparison of English versus the intermediates $(\underline{M}=3.0$ vs. $\underline{M}=2.73), \underline{t}(14)=2.26, \underline{p}<.05$. Also there was a significant comparison of advanced versus intermediates $(\underline{M}=3.0$ vs. $\underline{M}=2.73), \underline{t}$ $(14)=2.26, \underline{p}<.05$.

The tests, however, did not reveal any significance in the performance of the three groups in the written task on the choice of subject antecedents for pre-posed adjuncts with null subjects. Choice of a subject antecedent was unanimous for the English subjects and overwhelming for both the advanced and intermediate groups. The significant difference in performance in the act-out task was definitely not the result of language transfer since Spanish obligatorily requires a subject antecedent in similar constructions. A plausible explanation here is that intermediate subjects erroneously selected more non-subject antecedents as a result of processing constraints. In the act-out task, they had a limited time to select an antecedent (about 10 seconds) while they had unlimited time to select an antecedent for the written task. The pressure to select an antecedent within a limited time may have led to more erroneous choices.

Choice of a subject antecedent for post-posed adjuncts was the favourite for all three groups with comparable percentages in both the act-out and the written tasks. A one-way ANOVA test did not reveal any significant difference in the performance of the three subject groups.

\subsection{Act-out and written tasks: Experimental sentences}

The act-out and written tasks evaluated the interpretation pronominals in subjunctive and pre-posed adjunct constructions in English by native Spanish speakers. Co-indexation requirements in such constructions are restricted by pragmatic constraints in Spanish while co-indexation in English generally adheres to structural constraints of the binding theory. Pragmatic constraints prohibit the choice of a subject antecedent for pronominals in subjunctives and pre-posed adjuncts in Spanish. There are no such constraints in English. On the contrary, a matrix subject, though not obligatory, is the preferred antecedent in such constructions. The study evaluated the possibility of transfer of Spanish pragmatic constraints in the interpretation of pronominals in English as articulated by the pragmatic hypothesis is section 5 . This hypothesis stipulated that the saliency of pragmatic constraints governing co-indexation of pronominals in subjunctives and pre-posed adjunct constructions in Spanish would lead Spanish speakers to assume that such constraints were in operation in English as well.

\subsubsection{Interpretation of pronominals in subjunctive constructions}


Results of performance on the subjunctive constructions in the act-out and written tasks are presented in tables 3 and 4 respectively:

Table 3: Percentages of Subject Choice in Subjunctive Constructions (Act-out Task)

\begin{tabular}{llc}
\hline $\begin{array}{l}\text { Subjects } \\
\text { Match }\end{array}$ & Subject Match with Lead Sentence & No Subject \\
\hline English & $98.3(59 / 60)$ & $95 \%(57 / 60)$ \\
\hline Advanced & $90.7(49 / 54)$ & $90.7(49 / 54)$ \\
\hline Intermediate & $84.4(38 / 45)$ & $86.7(39 / 45)$
\end{tabular}

Table 4: Percentages of Subject Choice in Subjunctive Constructions (Written Task)

\begin{tabular}{llc}
\hline $\begin{array}{l}\text { Subjects } \\
\text { Match }\end{array}$ & Subject Match with Lead Sentence & No Subject \\
\hline English & $96.7 \%(58 / 60)$ & $96.7 \%(58 / 60)$ \\
\hline Advanced & $98.1 \%(53 / 54)$ & $98.1 \%(53 / 54)$ \\
\hline Intermediate & $93.3 \%(42 / 45)$ & $82.2 \%(37 / 45)$
\end{tabular}

As expected, a subject antecedent was the overwhelming choice ( $95 \%$ or higher) for the English group in both the act-out and written tasks, regardless of whether there was a match between the subjects of the subjunctive and the lead sentence. This was not surprising as a subject choice is preferred in such constructions in English.

A pragmatic requirement, however, prohibits a subject antecedent for a pronominal in subjunctives in Spanish. The Spanish subjects did not select a subject antecedent as frequently as the English subjects did; nevertheless, the choice of a subject antecedent was the preferred choice for both advanced and intermediate groups in both the act-out and written tasks, particularly the latter task. The intermediate group selected subject antecedents the fewest among the three groups. The difference in performance between the English and the intermediate groups in the act-out task with a subject match was $14 \%$, but an independent $t$-test revealed no significant difference in the performance of these two groups $(\mathrm{p} .=.09)$. The difference in performance between the advanced and intermediate groups for sentences with no subject match in the written task was close to $16 \%$, but an independent t-test revealed no significant difference in the performance of these two groups $(\mathrm{p}=.09)$. 
Effects of contextual information were also apparent for the intermediate group in selecting a subject antecedent in the Written experiment. Their performance was 11 percentage points better when contextual information was provided favouring a subject antecedent compared to when no such information was provided. This difference was however not statistically significant.

\subsubsection{Interpretation of pronominals in pre-posed adjunct constructions}

Results of performance on the Pre-posed adjunct constructions are illustrated in tables 5 and 6:

Table 5: Percentages of Subject Choice in Pre-posed Adjunct Constructions (Act-out Experiment)

\begin{tabular}{llc}
\hline $\begin{array}{l}\text { Subjects } \\
\text { Match }\end{array}$ & Subject Match with Lead Sentence & No Subject \\
\hline English & $100 \%(60 / 60)$ & $98.3 \%(59 / 60)$ \\
\hline Advanced & $98.1 \%(53 / 54)$ & $98.1 \%(53 / 54)$ \\
\hline Intermediate & $97.8 \%(44 / 45)$ & $80 \%(36 / 45)$
\end{tabular}

Table 6: Percentages of Subject Choice in Pre-posed Adjunct Constructions (Written Experiment)

\begin{tabular}{llc}
\hline $\begin{array}{l}\text { Subjects } \\
\text { Match }\end{array}$ & Subject Match with Lead Sentence & No Subject \\
\hline English & $98.3 \%(59 / 60)$ & $93.3 \%(56 / 60)$ \\
\hline Advanced & $100 \%(54 / 54)$ & $94.4 \%(51 / 54)$ \\
\hline Intermediate & $93.3(42 / 45)$ & $95.6 \%(43 / 45)$
\end{tabular}

The choice of a subject referent was predictably the overwhelming choice for the English speakers in both the act-out and written tasks, as this is the preferred choice in such constructions in English. Overt pronominals in pre-posed adjunct clauses in Spanish are however prohibited by a pragmatic requirement from having a matrix subject referent. In 
spite of different requirements in Spanish, the advanced group demonstrated knowledge of a subject referent being the preferred choice in English. Their scores were comparable to (sometimes higher than) those recorded for the English group. Results for the intermediate group were mixed. A subject referent was clearly the preferred choice in both act-out and written task, regardless of contextual information. However, while their scores were generally comparable to those recorded by the English and the advanced groups in the constructions preceded by a lead sentence with a subject match in both the act-out and written tasks, their scores in the act-out task when no subject match was provided in the lead sentence was significantly lower. A one-way ANOVA test revealed a significant difference among the three groups: $\underline{\mathrm{F}}(2,50)=5.97, \underline{\mathrm{p}}<.01$. Independent $\mathrm{t}$-tests further revealed the following significant differences: English $(\mathrm{M}=2.95)$ vs. intermediate $(\underline{\mathrm{M}}=$ $2.40), \underline{\mathrm{t}}(15.27)=2.29, \underline{\mathrm{p}}<.05$; advanced $(\underline{\mathrm{M}}=2.94)$ vs. intermediate $(\underline{\mathrm{M}}=2.40)$ is significant, $\underline{\mathrm{t}}(15.57)=2.25, \underline{\mathrm{p}}<.05$. There was no significant difference in choice of subject antecedents in the written task among the three groups.

Statistical analyses were also conducted to evaluate the effects of contextual information in the choice of a subject referent. Scores for the selection of a subject referent when there was a subject match for the lead and experimental sentences were compared to scores for the selection of a subject referent when there was no such match. This was done for both subjunctive and pre-posed adjunct constructions in both act-out and written tasks. A paired samples t-test revealed a significant effect of contextual information in the act-out task involving pre-posed adjunct constructions for the intermediate group: Pre-posed adjunct Subject Match $(\underline{\mathrm{M}}=2.93)$ vs. Pre-posed adjunct No Subject Match $(\underline{\mathrm{M}}=2.40)$, $(14)=2.28, \mathfrak{p}<.05$. This was the only segment of the study where effects of contextual information were significant.

\subsubsection{Discussion of results of interpretation of pronominals in subjunctives and pre-posed adjuncts}

Results of both the act-out and written tasks indicate an early reliance on L2 constraints governing co-indexation of pronominals in subjunctives and pre-posed adjuncts in English as evident in the performance of Spanish speakers at both intermediate and advanced competence levels in English. Pragmatic constraints, though salient in L1 (Spanish), were generally ignored. There was a strong preference for a subject referent for subjunctive and pre-posed adjunct constructions in English by both intermediate and advanced groups in the act-out and written tasks in spite of the different pragmatic requirements for similar constructions in Spanish. Percentage scores (of subject choice) for subjunctives and preposed adjuncts, which require obligatorily disjoint interpretation of pronominals in Spanish, were comparable to the percentage scores recorded for post-posed adjuncts, which have no requirement of obligatorily disjoint interpretation of pronominals in Spanish.

The prediction of the pragmatic hypothesis that Spanish pragmatic constraints would be transferred into English was not supported by results of the act-out and written tasks. For the most part, both intermediate and advanced groups recorded scores comparable to the English group in the act-out and written tasks. Worthy of note however is that though the intermediate group selected more subject antecedents than they did nonsubject antecedents for pre-posed adjunct constructions in the act-out task, results still 
revealed a significant difference in their performance compared to the advanced and English groups when no subject match was provided. This was the only aspect of both the act-out and written tasks in which there was a significant difference in subject performance. As mentioned earlier, the act-out task had a ten-second interval between sentences during which subjects were required to act the sentences out. The pressure to act out sentences within this time constraint particularly when no contextual information was provided might have been a mitigating factor in the significant difference in performance between the intermediate group and the other groups. It is thus plausible to postulate that lower proficient L2 learners may be more inclined transfer L1 pragmatic constraints in L2 when there are real-time processing constraints are imposed. In the written task, in which subjects had no time constraints, no significant difference was recorded in the performance of the three groups.

There was some evidence of the use of contextual information in resolving ambiguities in English anaphora. This was the case for the intermediate subjects. Their choice of subject referents for sentences with pre-posed adjuncts was likely enhanced as a result of saliency of the subject referent for constructions in which there was a subject match between the preceding lead sentence and the pre-posed adjunct construction. Use of contextual information was not an issue for the advanced subjects since their selection of subject referents was overwhelming for both subjunctives and pre-posed adjuncts with and without a subject match with the preceding lead sentence.

There was also some effect, though not significant, of competence level in the overall performance of the Spanish subjects. The intermediate group had fewer subject choices (the preferred English choice) for subjunctives and pre-posed adjuncts in both the act-out and the written tasks. A possible explanation is that less proficient subjects are more inclined to transfer L1 pragmatic properties than more proficient subjects.

\subsection{Grammaticality judgement task}

English and Spanish reflexives are generally obligatorily overt although the lexical properties of some English verbs allow reflexives to be implied (omitted). The Spanish equivalents of such verbs obligatorily require an overt reflexive marker (see examples in (17)). A similar phenomenon occurs with reciprocals as well (see examples in (18) and (19)). In intransitive constructions in English, the requirement is for the anaphora element to be obligatorily implied (omitted); in Spanish, it is required to be obligatorily overt (see examples in (20)). The lexical hypothesis, articulated in section 5, stipulated that the striking differences between the lexical requirements of anaphora and verbs in reflexive, reciprocal, and intransitive constructions in Spanish and English would result in an inappropriate transfer of such lexical properties in the judgment of similar constructions in English by native Spanish speakers. In the grammaticality judgment task, subjects were instructed to award a score ranging from 1 to 4 based on their judgment of the grammaticality of these constructions. A score of 4 was an indication that the construction was completely acceptable as a grammatical sentence in English. A score of 1 signified that the construction was completely unacceptable as grammatical to the subject. A score of 3 indicated that the construction was somewhat acceptable while a score of 2 signified that the construction was somewhat unacceptable. A tabulation of the results outlined the 
percentage of sentences awarded the maximum score of 4 as well as the mean score for each construction type for the three groups used in the study: Native English speakers; Spanish speakers with intermediate proficiency in English, and Spanish speakers with advanced proficiency in English. The prediction of the lexical hypothesis was for very few scores of 4 to be awarded by the Spanish subjects and for their mean scores to be significantly lower than the mean scores of the English subjects for constructions with implied anaphora elements compared to constructions with overt anaphora elements.

\subsubsection{Grammaticality judgment of constructions with overt/implied reflexives}

In reflexive constructions in English, if an implied reflexive is allowed, it is generally preferred over an overt reflexive. This was reflected on the scores of the English group in the grammaticality judgment task involving both constructions. See table 7:

Table 7: Percentages of Score 4 and Means (Max 4) of Sentences with Overt/Implied $\underline{\text { Reflexives }}$

\begin{tabular}{llclc}
\hline Subjects & \multicolumn{2}{l}{ OVERT REFLEXIVES } & \multicolumn{2}{c}{ IMPLIED REFLEXIVES } \\
& Means & Percentages & Means & Percentages \\
\hline English & 3.57 & $65 \%(39 / 60)$ & 3.62 & $73.3 \%(44 / 60)$ \\
\hline Advanced & 3.18 & $37 \%(20 / 54)$ & 3.56 & $68.5 \%(37 / 54)$ \\
\hline Intermediate & 3.38 & $60 \%(27 / 45)$ & 3.4 & $62.2 \%(28 / 45)$
\end{tabular}

The English group awarded the maximum score (4) $65 \%$ of the time with a mean score of 3.57 (out of a maximum of 4 ) for overt reflexives. The percentage and mean scores for implied reflexives were predictably but not significantly higher.

In spite of the differences between the lexical requirements of reflexive verbs in English and Spanish, both intermediate and advanced subjects demonstrated knowledge of not only the presence of implied reflexives but also the preference of such option in English. This knowledge was so strong that they had the tendency to reject grammatical overt reflexives. The grammaticality judgment task additionally requested subjects to rewrite, with suggested changes, all the sentences they awarded a score of less than 4 . The overt reflexives that the Spanish subjects awarded less than 4 were generally re-written as implied reflexives. The percentages of sentences that both groups awarded the score of 4 were much higher for implied than for overt reflexives. The mean scores for implied reflexives were also higher.

The percentages and mean scores of the Spanish subjects for overt reflexives were for the most part significantly lower than scores recorded for the English subjects. A oneway ANOVA test indicated significant differences in the performance of the subjects on 
the overt reflexives: $\underline{F}(2,50)=3.66, \underline{p}<.05$. Based on the rejection of the Levene's test, the tukey's test revealed significant difference in performance on the overt reflexives for the English group (1.95) vs. the advanced group (1.11), $\mathrm{p}<.05$. The advanced group consistently judged more implied reflexives as completely acceptable than the intermediate group did and was also less accepting of overt reflexives than the intermediate group. There was however no significant difference between the English and Spanish speakers on the implied reflexives.

On the basis of the performance of the Spanish subjects, one could conclude that they have likely developed a keen sensitivity to the lexical rules applied to English reflexives to an extent that they were guilty of hypercorrection. That is, they were very much aware of the preference for implied over overt reflexives that they might have misinterpreted preference for acceptability.

\subsubsection{Grammaticality judgment of constructions with overt/implied reciprocals}

Like reflexives in English, an implied reciprocal, if allowed, is generally preferred over an overt reciprocal. Results are presented in table 8:

Table 8: Percentages of Score 4 and Means (Max 4) of Sentences with Overt/Implied Reciprocals

\begin{tabular}{llclr}
\hline Subjects & OVERT RECIPROCALS & \multicolumn{2}{c}{ IMPLIED RECIPROCALS } \\
Means & Percentages & Means & Percentages \\
\hline English & 3.67 & $71.7 \%(43 / 60)$ & 3.83 & $88.3 \%(53 / 60)$ \\
\hline Advanced & 3.26 & $46.3 \%(25 / 54)$ & 3.97 & $96.3 \%(52 / 54)$ \\
\hline Intermediate & 3.31 & $53.3 \%(24 / 45)$ & 3.63 & $75.6 \%(34 / 45)$
\end{tabular}

The English group predictably judged more constructions with implied reciprocals more acceptable in percentage and mean scores than constructions with overt reciprocals. Constructions with overt reciprocals were nevertheless generally judged acceptable. The English group awarded the maximum score (4) $71.7 \%$ of the time for both overt reciprocals with a mean score of 3.67. Percentage and mean scores implied reciprocals were higher.

In spite of the different lexical requirements for reciprocal verbs in English and Spanish, Spanish subjects (both advanced and intermediate) demonstrated knowledge of the presence preference of implied reciprocals in English. As with the reflexive constructions, Spanish speakers at both proficiency levels in English tended to reject grammatical overt reciprocals and re-wrote the corrected versions as implied reciprocals. The percentage and mean scores for constructions with implied reciprocals were much higher than scores for overt and reciprocals. There was no support for the predictions of the 
lexical hypothesis that Spanish speakers would transfer the lexical requirements for Spanish verbs and anaphora elements in reciprocals in the use of reciprocals in English by native Spanish speakers.

The percentages and mean scores of both Spanish groups were generally significantly lower than scores recorded for the English subjects. A one-way ANOVA test also indicated significant differences in the performance of the subjects on the overt reciprocals: $\underline{\mathrm{F}}(2,50)=3.16, \underline{\mathrm{p}}=.05$. A conservative Dunnet $\mathrm{T} 3$ revealed a significant difference in performance on the overt reciprocals for the English group (2.15) vs. the advanced group (1.39), $\underline{p}<.05$. The advanced group consistently judged more implied reciprocals as completely acceptable than the intermediate group did. The advanced group further judged fewer overt reciprocals as completely acceptable compared to the intermediate group. There was no significant difference in the judgment of implied reciprocals between the English and Spanish speakers.

As was postulated for the reflexive constructions, the Spanish subjects had likely developed a keen sensitivity to the lexical rules applied to English reciprocals and were probably guilty of hypercorrection in judging overt reciprocals as less than completely acceptable. As with the reflexive constructions, they might have misinterpreted preference for acceptability.

\subsubsection{Grammaticality judgment of constructions with overt/implied intransitives}

English and Spanish have conflicting lexical requirements for verbs used in intransitive constructions. Obligatory retention of /se/ is required by Spanish verbs (see examples in (20)) while similar verbs in English require obligatory omission of the anaphora element. It is implied. Results of the study, illustrated in table 9, indicated native Spanish speakers' knowledge of this requirement in English:

Table 9: Percentages of Score and Means (Max 4) of Sentences with Overt/Implied Intransitives

\begin{tabular}{lcccc}
\hline Subjects & \multicolumn{2}{c}{$\begin{array}{l}\text { OVERT INTRANSITIVES } \\
\text { Means }\end{array}$} & Percentages & \multicolumn{2}{c}{$\begin{array}{l}\text { IMPLIED INTRANSITIVES } \\
\text { Means }\end{array}$} & $\begin{array}{c}\text { Percentages } \\
\text { English }\end{array}$ & 2.13 & $5 \%(3 / 60)$ & 3.93 & $91.7 \%(55 / 60)$ \\
\hline Advanced & 2.46 & $1.9 \%(1 / 54)$ & 3.82 & $85.2 \%(46 / 54)$ \\
\hline Intermediate & 2.99 & $28.9 \%(13 / 45)$ & 3.73 & $86.7 \%(39 / 45)$ \\
\hline
\end{tabular}

The English control group demonstrates knowledge of this requirement as they awarded a maximum score (4) only $5 \%$ of the time for overt intransitives compared to $91.7 \%$ of the time for implied intransitives. The mean scores also reflected this knowledge: 2.13 for overt intransitives compared to 3.93 for implied intransitives. 
In spite of the different lexical requirements for intransitives in Spanish and English, Spanish speakers at different competence levels were aware of the English lexical requirements and, like the English subjects, consistently rejected sentences with overt anaphora elements and awarded impressive mean and percentage scores to sentences with implied anaphora elements. Both groups awarded the maximum score (4) over $85 \%$ of the time with mean scores not much different from those of the English group. The judgment of the Spanish subjects thus did not provide support for the lexical hypothesis that the Spanish lexical requirement of obligatory retention of the anaphora elements in intransitives would be transferred in the use of such constructions in English.

An interesting revelation was that the intermediate group awarded a much higher mean (2.99) for overt intransitives than the advanced and the English groups, which recorded means of 2.46 and 2.13 respectively. The intermediate group further judged $28.9 \%$ of overt intransitives as completely acceptable (i.e. a score of 4 was awarded). This was much higher than percentage scores judged as such by the advanced (1.9\%) and English $(5 \%)$ groups. A one-way ANOVA test indicated significant differences in the performance of the subjects on the overt intransitives: $\underline{\mathrm{F}}(2,50)=7.44, \underline{\mathrm{p}}<.001$. The Dunnet T3 test revealed a significant difference in the performance of the intermediate and advanced groups on the overt intransitive constructions: Advanced (.06) vs. intermediate (.87), $\mathfrak{p}<$ .05. Nevertheless, the intermediate group's score for the overt intransitives was much lower than its score for implied intransitives. There was no significant difference among the performance of the different groups on implied intransitives.

\subsubsection{Grammaticality judgment of ungrammatical filler sentences}

A number of obviously ungrammatical sentences were included in the grammaticality judgement tasks as detractors. The results of the performance of the different groups for these sentences are presented in table 10:

Table 10: Percentages of Score 4 and Means (Max 4) of Ungrammatical Sentences

\begin{tabular}{|c|c|c|}
\hline \multirow[t]{2}{*}{ Subject } & \multicolumn{2}{|c|}{ UNGRAMMATICAL SENTENCES } \\
\hline & Means & Percentages \\
\hline English & 1.12 & $0 \%(0 / 60)$ \\
\hline Advanced & 1.14 & $0 \%(0 / 54)$ \\
\hline Intermediate & 1.57 & $7.1 \%(3 / 42)$ \\
\hline
\end{tabular}

Both Spanish and English subjects were aware that these sentences, included in the experiments as fillers, were ungrammatical as is evident in the low scores recorded across the board. 


\subsubsection{Discussion of results on grammaticality judgement task}

Results of the grammaticality judgement task revealed that native Spanish speakers, at different proficiency levels in English, were aware of the different lexical of verbs and anaphora elements in reflexive, reciprocal, and intransitive constructions in English and Spanish. This was evident in the performance of Spanish speakers at both intermediate and advanced competence levels in English. Grammaticality judgements of English sentences with implied reflexives, reciprocals, and intransitives by Spanish subjects at both competence levels were to a large extent similar to the judgments of the native English speakers in spite of the fact that such constructions are not allowed in Spanish. Overt reflexives and reciprocals, which are obligatory in Spanish but less preferred in English, were sometimes rejected and generally awarded lower percentage and mean scores than the implied reflexives and reciprocals. Overt anaphora elements in intransitives, which are obligatory in Spanish but prohibited in English, were generally rejected by native Spanish speakers in their judgement of intransitive constructions in English. There was thus no support for the lexical hypothesis that striking differences between lexical requirements in reflexives, reciprocals, and intransitives would trigger a transfer of the Spanish lexical properties in the use of similar properties in English as L2.

There was some effect of competence level in the overall performance of the Spanish subjects. The Intermediate group awarded fewer scores of 4 for implied reflexives and reciprocals and recorded lower mean scores as well. These differences were however not significant. More importantly, though, the Intermediate group accepted a significantly larger number of overt intransitives, which are allowed in English but not in Spanish. It is unlikely that this was due to transfer since they awarded scores of 4 for implied intransitives much more frequently than they did for overt intransitives. The mean for implied intransitives was much higher as well. A likely explanation is that they might have over-generalized the rule for reflexives and reciprocals to include intransitives. The lexical items used for these three constructions in Spanish are homophonous - /se/. They may have therefore concluded that the properties of reflexives and reciprocals were also inherent in intransitives, i.e. that overt reflexives and reciprocals, and, by implication, intransitives, were less preferred but not ungrammatical.

\section{Concluding remarks}

Results of the study indicated either a relatively early acquisition of English pragmatic and lexical requirements governing the interpretation of anaphora or an early realization that Spanish pragmatic and lexical constraints did not transfer into English. Contrary to the predictions of the pragmatic and lexical hypotheses, Spanish speakers demonstrated an early awareness of the different requirements for the anaphoric resolution in English. They were aware that the pragmatic constraints governing co-indexation in subjunctives and preposed adjuncts were not applicable in English, and that the different lexical requirements governing the use of anaphoric elements in reflexives, reciprocals, and intransitives were different in Spanish and English. There was no evidence of transfer of L1 pragmatic and lexical constraints into L2. The intermediate group further demonstrated the inclination to 
utilize contextual information, when available, in the act-out task involving pre-posed adjuncts.

This study evaluated in part the possibility of transfer of pragmatic constraints governing co-indexation of anaphora from Spanish - a 'pragmatic' language - to English a 'syntactic' language. Results indicated that Spanish speakers were able to ignore the pragmatic constraints of Spanish and rely primarily on the structural constraints of English in their interpretation of pronominals in subjunctives and pre-posed adjuncts in English. Co-indexation of pronominals in subjunctives and pre-posed adjuncts in Spanish - a null pronominal language - is governed by the principles of emphaticness and contrast (discussed in section 3.3). English - a non-null pronominal language - does not have an alternation of overt and null pronominals in the same position in a sentence. The Spanish subjects, who were categorized as having intermediate and advanced competence in English, were aware that these principles did not apply in English. One could hypothesize then that the transfer of Spanish pragmatic rules for anaphoric resolution occurs before the realization that English, a non-pronominal language, does not apply these principles. To test this hypothesis, this study would have to be replicated with the inclusion of an additional group of subjects - Spanish speakers who are beginner learners of English.

Results of the study further revealed that speakers of a 'pragmatic' L1 did not have difficulty with anaphoric co-indexation in a 'syntactic' L2. That is, speakers of a 'pragmatic' $\mathrm{L} 1$ could successfully block the transfer of L1 pragmatic constraints into L2. What is not certain, however, is whether the reverse would be true: Whether speakers of a 'syntactic' L1 would have difficulty acquiring a 'pragmatic' L2, in which pragmatic constraints further restrict the structural constraints on co-indexation of pronominals. Future research involving native English speakers interpreting pronominals in subjunctives and pre-posed adjuncts in Spanish could provide additional information on the possible successful acquisition and application of pragmatic constraints in L2.

Results further indicated a successful blocking of the transfer of L1 (Spanish) lexical properties of obligatory retention of anaphora in reflexives, reciprocals, and intransitives into L2 (English). Future research could be extended to evaluate the possibility of native English speakers transferring the lexical properties of optional and obligatory deletion of anaphora in similar constructions in Spanish.

\section{References}

Altmann, G. (1988 Ambiguity parsing strategies and computational models. Language and Cognitive Processes 3: 73-97.

Borer, H. (1984) Parametric Syntax. Dordrecht: Foris Publications.

Dalrymple, M. (1993) The ssyntax of anaphoric binding. center for the study of language and information (CSLI).

Freiden, R. (1986) Fundamental issues in the theory of binding. In B. Lust (ed.), Studies in the Acquisition of Anaphora, volume 1. Dordrecht: D. Reidel Publishing Company.

Huang, Y. (2000) Anaphora: A Cross-linguistic Study. Oxford: Oxford University Press. 
Jaeggli, O. (1986) Arbitrary plural pronominals. Natural Language and Linguistic Theory 4: 43-76.

Lujan, M. (1985). Binding properties of overt pronouns in null pronominal languages. (manuscript) The University of Texas.

Lujan, M. (1986) Stress and binding of pronouns. Papers from the Parasession on Pragmatics and Grammatical Theory, Chicago Linguistic Society.

Montalbetti, M. (1984) After binding: On the interpretation of pronouns. Ph.D. Dissertation, M.I.T.

Padilla, J. (1990) On the Definition of Binding Domains in Spanish: Evidence from Child Language. Deventer: Kluwer Academic Publishers.

Pulleyblank, D. (1986) Clitics in Yoruba. In H. Borer (ed.), Syntax and Semantics: The Syntax of Pronominal Clitics. New York: Academic Press.

Taraban, R., and J. McClelland (1988) Constituent attachment and thematic role assignment in sentence processing: Influence of content-based expectations. Journal of Memory and Language 27: 597-632.

Wexler, K., and M. Manzini (1987) Parameters and learnability in binding theory. In T. Roeper, \& E. Williams (eds.), Parameter Setting. Dordrecht: D. Reidel Publishing Company, pp. 123-172.

Whitley, M.S. (1986) Spanish/English Contrasts: A Course in Spanish Linguistics. Washington, D.C.: Georgetown University Press.

\section{Appendix}

\section{ACT-OUT ANAPHORA EXPERIMENT}

INSTRUCTIONS: In this experiment, you will be using these dolls (Dad, Mom, Tom, Jack, Kate and Sue) to act out sentences. For example:

Tom runs up to Sue

Here are some to practice with. Make the dolls do what I say:

Dad hugs mom

Mom walks away from Tom and sits down

Ready? Make the dolls do what I say:

1. Mom sings to Kate after she plays with the dog

2. After singing a song, Tom waves to Jack

3. After reading a book, Sue kisses mom

4. Jack runs up to dad after he reads the book

5. Tom hugs dad after he dances with Sue

6. After running around the block, Kate dances with Sue 
Now I'm going to say two things; wait till I finish and make them do the last thing I say

7. The family loves eating fruits

After he eats an orange, Tom lifts Jack

8. Mom likes kissing the family

Mom proposes that she kiss Tom

9. Sue likes going for a walk

After she goes for a walk, Sue reads to Kate

10. The family likes reading books and magazines

Dad demands that he read the book

11. Jack loves jumping over the gate

Jack requests that he jump over the gate

12. Dad loves hugging the family

After he hugs Kate, dad lifts Jack

13. The family loves singing to each other

Kate suggests that she sing to dad

14. The family loves kissing each other

After she kisses dad, Kate runs up to Sue

15. Kate likes sitting on the block

After she sits on the block, Kate jumps over Sue

16. The family loves dancing with each other

Sue recommends that she dance with Jack

17. The family loves singing to each other

After he sings to mom, Jack hugs dad

18. Tom likes sitting on the block

Tom insists that he sit on the block

\section{WRITTEN ANAPHORA EXPERIMENT: QUESTIONNAIRE 1}

INSTRUCTIONS: This experiment contains questions that are preceded by one or two sentences. Please read the sentences and select an answer for each question that follows:

1. After cleaning his room, Tom sings to Jack
Question: Who was cleaning his room?
a) Tom
b) Jack
c) dad

2. Tom hugs dad after he sings a song
$\mathrm{Q}$ : Who was singing a song?
a) dad
b) Tom
c) Jack

3. Kate jumps over Sue after she cleans the house
$\mathrm{Q}$ : Who was cleaning the house?
a) mom
b) Kate
c) Sue

4. After having a bath, dad reads to mom $\mathrm{Q}$ : Who was having a bath?
a) dad
b) mom
c) Tom

5. Jack tickles Tom after he eats a banana
$\mathrm{Q}$ : Who was eating a banana?
a) Tom
b) Jack
c) dad 
6. After preparing dinner, Sue jumps over Kate

$\mathrm{Q}$ : Who was preparing dinner?
a) mom
b) Kate
c) Sue

7. The family likes exercising in the gym

Dad proposes that he exercise in the gym

$\mathrm{Q}$ : Who is likely to exercise in the gym

a) dad

b) Jack

c) Tom

8. Tom likes listening to music

After he listens to music, Tom dances with dad

Q: Who was listening to music? $\quad$ a) dad

b) Tom $\quad$ c) Jack

9. Jack loves working in the garden Jack requests that he work in the garden $\mathrm{Q}$ : Who is likely to work in the garden?
a) Tom
b) dad
c) Jack

10. The family likes running around the house After he runs around the house, Sue dances with Kate
$\mathrm{Q}$ : Who was running around the house?
a) Kate
b) Sue
c) mom

11. Jack loves playing tennis After he plays tennis, Jack lifts Tom Q: Who was playing tennis?
a) Jack
b) Tom
c) dad

12. Kate likes going for a swim

Kate insists that she go for a swim

$\mathrm{Q}$ : Who is likely to go for a swim?
a) mom
b) Kate
c) Sue

13. The family likes dancing After he dances, dad hugs Tom

$\mathrm{Q}$ : Who was skating on the canal?
a) Tom
b) Jack
c) dad

14. The family likes baking cakes

Mom recommends that she bake a cake
$\mathrm{Q}$ : Who is likely to bake a cake?
a) Sue
b) mom
c) Kate

15. Sue loves playing the piano

Sue demands that she play the piano

$\mathrm{Q}$ : Who is likely to play the piano?
a) Sue
b) mom
c) Kate

16. The family loves watching TV

After she watches TV, mom reads to Sue
Q: Who was watching TV?
a) Kate
b) Sue
c) mom

17. Kate likes doing the laundry After she does the laundry, Kate sings to mom
$\mathrm{Q}$ : Who did the laundry?
a) Sue
b) mom
c) Kate 
18. The family loves riding their bikes

Tom suggests that he ride the bike

$\mathrm{Q}$ : Who is likely to ride the bike?
a) Tom
b) Jack
c) dad

\section{GRAMMATICALITY JUDGEMENT TASK: QUESTIONNAIRE 1}

Rank the following sentences in English according to the following scale:

4) Grammatical 3) Somewhat Grammatical 2) Somewhat Ungrammatical 1) Ungrammatical

For those ranked less than (4), please provide a grammatical equivalent or preferred alternative on the line below each sentence.

1. Peter washed after working on his car

\begin{tabular}{|l|l|l|l|}
\hline 4 & 3 & 2 & 1 \\
\hline
\end{tabular}

2. The couple that lived next door got divorced from each other last month

\begin{tabular}{|l|l|l|l|}
\hline 4 & 3 & 2 & 1 \\
\hline
\end{tabular}

3. The wine spilled on the floor

\begin{tabular}{|l|l|l|l|}
\hline 4 & 3 & 2 & 1 \\
\hline
\end{tabular}

4. The waiter the tray dropped while it carrying to the table

\begin{tabular}{|l|l|l|l|}
\hline 4 & 3 & 2 & 1 \\
\hline
\end{tabular}

5. Susan dressed herself before attending the dinner

\begin{tabular}{|l|l|l|l|}
\hline 4 & 3 & 2 & 1 \\
\hline
\end{tabular}

6. The boys fought over an apple

\begin{tabular}{|l|l|l|l|}
\hline 4 & 3 & 2 & 1 \\
\hline
\end{tabular}

7.The glasses in the cabinet broke themselves during the earthquake

\begin{tabular}{|l|l|l|l|}
\hline 4 & 3 & 2 & 1 \\
\hline
\end{tabular}

8. Ben the book read before it to Terry he gave

\begin{tabular}{|l|l|l|l|}
\hline 4 & 3 & 2 & 1 \\
\hline
\end{tabular}


9. Dave shaves everyday before going to work

\begin{tabular}{|l|l|l|l|}
\hline 4 & 3 & 2 & 1 \\
\hline
\end{tabular}

10. The two men argued with each other over who should be the team leader \begin{tabular}{|l|l|l|l|}
\hline 4 & 3 & 2 & 1 \\
\hline
\end{tabular}

11. The ice cream melted after it was taken from the freezer

\begin{tabular}{|l|l|l|l|}
\hline 4 & 3 & 2 & 1 \\
\hline
\end{tabular}

12. Very much my cousin the girl next door likes

\begin{tabular}{|l|l|l|l|}
\hline 4 & 3 & 2 & 1 \\
\hline
\end{tabular}

13. Sally drives herself to the movies on weekends

\begin{tabular}{|l|l|l|l|}
\hline 4 & 3 & 2 & 1 \\
\hline
\end{tabular}

14. Tom and Laura got married on Valentine's Day

\begin{tabular}{|l|l|l|l|}
\hline 4 & 3 & 2 & 1 \\
\hline
\end{tabular}

15. The boat sank itself during the storm

\begin{tabular}{|l|l|l|l|}
\hline 4 & 3 & 2 & 1 \\
\hline
\end{tabular}

16. Getting married the geography teacher next month is \begin{tabular}{|l|l|l|l|}
\hline 4 & 3 & 2 & 1 \\
\hline
\end{tabular}

17. The football players bathe after practice every evening \begin{tabular}{|l|l|l|l|}
\hline 4 & 3 & 2 & 1 \\
\hline
\end{tabular}

18. The students agreed with each other that the teacher was a nice man \begin{tabular}{|l|l|l|l|}
\hline 4 & 3 & 2 & 1 \\
\hline
\end{tabular}

19. The ball that was in the box rolled down the hill \begin{tabular}{|l|l|l|l|}
\hline 4 & 3 & 2 & 1 \\
\hline
\end{tabular}

20. A new dorm they are on campus building 


\section{\begin{tabular}{|l|l|l|l|}
\hline 4 & 3 & 2 & 1 \\
\hline
\end{tabular}}

21. Jane rushed herself to the hospital when she hurt her leg \begin{tabular}{|l|l|l|l|}
\hline 4 & 3 & 2 & 1 \\
\hline
\end{tabular}

22. The two dogs struggled over a bone

\begin{tabular}{|l|l|l|l|}
\hline 4 & 3 & 2 & 1 \\
\hline
\end{tabular}

23. The paper that was on the stove burned itself

\begin{tabular}{|l|l|l|l|}
\hline 4 & 3 & 2 & 1 \\
\hline
\end{tabular}

24. His assignment didn't the lazy student on time hand in

\begin{tabular}{|l|l|l|l|}
\hline 4 & 3 & 2 & 1 \\
\hline
\end{tabular}

